\title{
Dedicated bifurcation stents or regular drug eluting stents in distal left main stenosis: A retrospective study
}

\author{
Adam Kern ${ }^{1,2}$, Robert J. Gil ${ }^{3,4}$, Krystian Bojko², Bartłomiej Rzeszowski², \\ Krzysztof Bednarski ${ }^{1,5}$, Jerzy Górny ${ }^{2}$, Jacek Bil ${ }^{3}$ \\ ${ }^{1}$ Department of Cardiology and Cardiosurgery, University of Varmia and Masuria, Olsztyn, Poland \\ ${ }^{2}$ Department of Cardiology, Regional Specialist Hospital in Olsztyn, Poland \\ ${ }^{3}$ Department of Invasive Cardiology, Central Clinical Hospital of the \\ Ministry of Interior and Administration, Warsaw, Poland \\ ${ }^{4}$ Institute of Experimental and Clinical Medicine, Polish Academy of Science, Warsaw, Poland \\ ${ }^{5}$ Dialysis Center Fresenius Nephrocare, Ostroda, Poland
}

\begin{abstract}
Background: In the distal left main (LM) atherosclerosis mainly develops within bifurcation or trifurcation. The aim of this study was to analyze the strategy of distal LM stenosis treatment and associated clinical outcomes in a large hospital in Northern Poland.

Methods: The study population consisted of consecutive patients with stable coronary artery disease or acute coronary syndrome (ACS) and distal LM stenosis who were hospitalized between June 2012 and June 2013. Patients were treated with regular drug-eluting stents ( $r D E S)$, including bioresorbable vascular scaffolds, or dedicated bifurcation stents (BiOSS LIM ${ }^{\circledR}$ ). Clinical outcomes were analyzed at 12, 24 and 36 months. Primary endpoint was cumulative major adverse cardiovascular events (MACE) inducing rate of cardiac death, myocardial infarction, and target lesion revascularization (TLR) after 36 months.

Results: One hundred and two patients were identified, 90 of whom were treated with percutaneous coronary intervention (56 rDES, including 9 Absorb, and 34 BiOSS) with no stent implantation failure. In 15 (16.7\%) patients rDES was required within side branch (SB). After 36 months MACE rate was $19.0 \%$ (BiOSS: $18.8 \%$ vs. rDES 19.2\%), whereas TLR rate was $10.7 \%$ (BiOSS $12.5 \%$ vs. rDES 9.6\%). In logistic regression for 36-month TLR rate proximal optimization technique (OR 0.311, 95\% CI 0.211-0.644) was a prognostic factor of better clinical outcome, whereas non-ST-elevation ACS (OR 2.211, 95\% CI 1.642-5.110), ST-elevation myocardial infarction (OR 2.771, 95\% CI 1.325-7.209) and SB stenting (OR 1.141, 95\% CI 1.002-1.881) were risk factors of poor outcome.

Conclusions: Regular drug-eluting stents as well as dedicated bifurcation BiOSS LIM ${ }^{\circledR}$ stents enabled a simple and fast distal LM treatment option with a single stent. Both resulted in comparable MACE and TLR rates. (Cardiol J 2018; 25, 2: 188-195)
\end{abstract}

Key words: BiOSS, culotte technique, dedicated bifurcation stent, provisional T-stenting

\section{Introduction}

Results of randomized trials and observational studies showed that percutaneous coronary intervention $(\mathrm{PCI})$ is a potential alternative to bypass surgery for patients with unprotected left main
(LM) coronary artery stenosis [1, 2]. Moreover, 2 recent meta-analyses showed that primary endpoint of 1-year major adverse cardiac and cerebral events was non-significantly different in PCI group compared with the coronary artery bypass grafting (CABG) one, $14.5 \%$ and $11.8 \%, \mathrm{p}=0.11$, respectively [3-5].

Address for correspondence: Adam Kern, MD, PhD, Department of Cardiology and Cardiosurgery, University of Varmia and Masuria, ul. Żołnierska 18, 10-561 Olsztyn, Poland, e-mail: adamkern@mail.com 
In most cases atherosclerosis develops in the distal part of $\mathrm{LM}$ within bifurcation or trifurcation [6]. In general, based on non-randomized studies and extrapolations from the results of non-LM bifurcation trials, the provisional 1-stent approach has been considered a preferred strategy over the elective 2-stent technique for patients with LM bifurcation disease. In practice, however, 2 -stent techniques are chosen more frequently for LM bifurcation than for non-LM lesions due to concerns regarding the ischemic myocardial volume, which would be jeopardized by adverse events [7].

The aim of this study was to analyze the strategy of distal LM stenosis treatment and associated clinical outcomes in a large hospital in Northern Poland.

\section{Methods}

\section{Study population and study design}

It was a retrospective registry conducted between June 2012 to June 2013 in a high-volume center (> 1500 PCI per year) in Poland (Olsztyn). The local database was searched for patients with LM stenosis treatment on 12.09.2016. The inclusion criteria were: age $\geq 18$ years old and distal LM stenosis qualified for PCI. Present CABG treatment was the exclusion criterion. All patients with symptomatic stable coronary artery disease (CAD), non ST-elevation acute coronary syndrome (NSTE-ACS) as well as ST-elevation myocardial infarction (STEMI) were taken into account. Patients were contacted by telephone to obtain follow-up data. The Institutional Review Board approved the study protocol.

\section{Interventional procedure \\ and concomitant medications}

Single stent implantation was the default strategy [8]. Bifurcation lesions were assessed according to Medina classification using an index of 1 for stenosis greater than $50 \%$ and 0 for no stenosis (visual estimation) [9]. There was no restriction regarding lesion length in patient selection. The main indication for using dedicated bifurcation stents was the ratio of proximal main vessel (MV) diameter to distal MV diameter $>1.2$. If required, additional regular DES (rDES) was implanted. A stent in the side branch (SB) was implanted only if there was a proximal residual stenosis greater than $70 \%$ after balloon dilatation and/or a significant flow impairment after proximal MV - distal MV stenting and/or a flow limiting dissection.

In patients with STEMI or NSTE-ACS loading dose of clopidogrel $(600 \mathrm{mg})$, ticagrelor $(180 \mathrm{mg})$ or prasugrel (60 mg) was given, and, if also needed, a loading dose of acetylsalicylic acid (ASA) was applied (300 mg). In planned procedures $72 \mathrm{~h}$ before PCI each patient received ASA (75 mg/24 h) and clopidogrel $(75 \mathrm{mg} / 24 \mathrm{~h})$. All procedures were performed in a standard way via radial or femoral access using 6 Fr or 7 Fr guiding catheters. After insertion of the arterial sheath each patient received unfractionated heparin (70-100 IU/kg). Additional bolus was given to maintain activated clotting time $>250$ s. Dual antiplatelet therapy (ASA $75 \mathrm{mg}$ q.d. and clopidogrel $75 \mathrm{mg}$ q.d., prasugrel $10 \mathrm{mg}$ q.d. or ticagrelor $90 \mathrm{mg}$ b.i.d.) was prescribed for 12 months.

All patients had troponin I, creatine kinase (CK) and CK-MB levels examined before the procedure, $6 \mathrm{~h}$ and $24 \mathrm{~h}$ afterwards. Periprocedural myocardial infarction (MI; type 4a) was assessed according to the third universal definition [10].

\section{Device description}

Second generation drug-eluting stents (DES) available in the cath lab, Absorb bioresorbable vascular scaffold (BVS) (Abbott, USA) and dedicated bifurcation stent BiOSS LIM ${ }^{\circledR}$ (Balton, Poland) could have been used [11].

\section{Endpoints}

The primary endpoint was the cumulative rate of major adverse cardiovascular events (MACE) including cardiac death, $\mathrm{MI}$ and repeated revascularization of the target lesion (TLR) at 3 years. The secondary endpoints included cardiac death, all-cause death, MI, and TLR at 1-, 2- and 3-year follow-up. All deaths were deemed cardiac unless proven otherwise.

\section{Statistical analysis}

Continuous variables were presented as mean \pm standard deviation. Categorical data were presented as numbers (\%). Continuous variables were compared using an unpaired Student $\mathrm{t}$ test, and categorical data using the $\chi^{2}$ test or Fisher exact test, as appropriate. If distribution was not normal, Wilcoxon signed-rank tests and Mann-Whitney $\mathrm{U}$-tests were used. $\mathrm{P}$ values of $<0.05$ were considered statistically significant. Also, univariate and multivariate logistic regression analysis were performed. Statistical analyses were performed using R 3.0.2 for OS (R Foundation, Vienna, Austria).

\section{Results}

\section{Baseline clinical characteristics}

Between June 2012 and June 2013102 patients with distal LM stenosis were identified. 
Table 1. Demographics.

\begin{tabular}{lc}
\hline Parameter & $\begin{array}{c}\text { No. of patients } \\
\mathbf{n}=90(\%)\end{array}$ \\
\hline Age [years] & $65.6 \pm 8.0$ \\
Women & $24(26.7 \%)$ \\
Stable CAD & $59(65.5 \%)$ \\
NSTE-ACS & $27(30 \%)$ \\
STEMI & $4(2.5 \%)$ \\
Hypertension & $78(86.7 \%)$ \\
Dyslipidemia & $81(90 \%)$ \\
Diabetes type 2 & $33(36.7 \%)$ \\
Prior MI & $60(66.7 \%)$ \\
Prior PCl & $54(60 \%)$ \\
Prior CABG & $33(36.7 \%)$ \\
Lower extremity artery disease & $9(10 \%)$ \\
Carotid artery disease & $9(10 \%)$ \\
Chronic kidney disease & $12(13.3 \%)$ \\
Smoking & $27(30 \%)$ \\
\hline
\end{tabular}

CABG — coronary artery bypass graft; CAD — coronary artery disease; NSTE-ACS - non-ST-elevation acute coronary syndrome; $\mathrm{Ml}$ - myocardial infarction; $\mathrm{PCl}$ - percutaneous coronary intervention

Table 2. Lesion and stent characteristics.

\begin{tabular}{lc}
\hline Lesion characteristics & $\begin{array}{c}\text { No. of lesions } \\
\mathbf{n}=90(\%)\end{array}$ \\
\hline Medina type: & $15(16.7 \%)$ \\
1.1 .1$. & $24(26.7 \%)$ \\
1.1 .0$. & $13(14.4 \%)$ \\
1.0 .1$. & $18(20.0 \%)$ \\
0.1 .1$. & $14(15.6 \%)$ \\
1.0 .0$. & $6(6.7 \%)$ \\
0.1 .0 & $22.39 \pm 7.48$ \\
SYNTAX score & \\
Lesion type: & $0(0 \%)$ \\
A & $5(5.6 \%)$ \\
B1 & $57(63.3 \%)$ \\
B2 & $28(31.1 \%)$ \\
C & \\
Stent type: & $56(62.2 \%)$ \\
Regular DES: & $29(32.2 \%)$ \\
Sirolimus eluting stent & $18(20.0 \%)$ \\
Everolimus eluting stent & $9(10.0 \%)$ \\
Bioresorbable vascular scaffold & $34(37.8 \%)$ \\
Dedicated bifurcation stent BiOSS LIM & \\
\hline
\end{tabular}

DES - drug eluting stent
Table 3. Procedural characteristics.

\begin{tabular}{lc}
\hline Parameter & $\begin{array}{c}\text { No. of lesions } \\
\mathbf{n}=90(\%)\end{array}$ \\
\hline Successful implantation & $90(100 \%)$ \\
Main vessel predilatation & $69(76.7 \%)$ \\
Side branch predilatation & $45(50.0 \%)$ \\
Both branches predilatation & $9(10.0 \%)$ \\
Regular DES nominal & $3.79 \pm 0.45$ \\
parameters [mm] & $\times 17.0 \pm 6.60$ \\
Dedicated bifurcation stent & $3.98 \pm 0.32$ \\
nominal parameters & $\times 3.23 \pm 0.33$ \\
(proximal diameter $\times$ distal & $\times 16.92 \pm 2.99$ \\
diameter $\times$ length) [mm] & \\
Side branch postdilatation & $33(36.7 \%)$ \\
Proximal optimization technique & $51(56.7 \%)$ \\
Final kissing balloon & $39(43.3 \%)$ \\
Additional stent in side branch & $15(16.7 \%)$ \\
Fluoroscopy time [min] & $18.8 \pm 10.6$ \\
Contrast volume [mL] & $244 \pm 150$ \\
Vascular access femoral/radial & $6.7 \% / 93.3 \%$ \\
Guiding catheter 6 F/7 F & $100 \% / 0 \%$ \\
Double-stent technique: & $\mathrm{N}=15(\%)$ \\
T-stenting & $2(13.3 \%)$ \\
T-and-protrusion technique & $7(46.7 \%)$ \\
Mini-crush & $2(13.3 \%)$ \\
Culotte & $4(26.7 \%)$ \\
\hline
\end{tabular}

DES - drug-eluting stent

Nevertheless, 90 patients were qualified for PCI and only those patients were further analyzed (12 patients were referred to CABG). The mean age was $65.6 \pm 8$ years and women stand for $26.7 \%$ $(\mathrm{n}=24)$ of the population. Most patients had stable CAD $(\mathrm{n}=59,65.5 \%)$, hypertension $(\mathrm{n}=78$, $86.7 \%)$ and dyslipidemia $(\mathrm{n}=81,90 \%)$. The detailed data are presented in Table 1.

\section{Angiographic and procedural characteristics}

The bifurcation lesions were most frequently assessed as type B2 ( $\mathrm{n}=57,63.3 \%)$, and true bifurcations stand for 46 (51.1\%) treated lesions. Only DES were deployed among which most frequently rDES were used $(\mathrm{n}=56,62.2 \%)$, including bioresorbable vascular scaffold systems $(n=9)$, and were followed by dedicated bifurcation BiOSS LIM stents $(\mathrm{n}=34,37.8 \%)$ (Table 2$)$.

The main procedural aspects are presented in Table 3. All stents were successfully implanted. In $15(16.7 \%)$ cases the additional stent was implanted into the SB, mainly using T-and-protrusion 
Table 4. Clinical results.

\begin{tabular}{lccc}
\hline & 1-year FU (n= 84) & 2-year FU (n = 84) & 3-year FU (n = 84) \\
\hline MACE & $8(9.5 \%)$ & $12(14.3 \%)$ & $16(19.0 \%)$ \\
All-cause death & $2(2.4 \%)$ & $3(3.6 \%)$ & $5(5.9 \%)$ \\
Cardiac death & $1(1.2 \%)$ & $2(2.4 \%)$ & $2(2.4 \%)$ \\
Myocardial infarction & $2(2.4 \%)$ & $3(3.6 \%)$ & $5(5.9 \%)$ \\
Stent thrombosis & $0(0 \%)$ & $0(0 \%)$ & $0(0 \%)$ \\
Target lesion revascularization & $5(5.9 \%)$ & $7(8.3 \%)$ & $9(10.7 \%)$ \\
\hline
\end{tabular}

FU — follow-up; MACE - major adverse cardiovascular events

or culotte techniques. Final kissing balloon ended $43.3 \%$ of procedures.

\section{Clinical outcomes}

During the in-hospital period 6 deaths occurred. They were caused by: multi-organ failure as a result of persisting cardiogenic shock $(n=5)$ or cardiac tamponade as a result of free wall rupture $(\mathrm{n}=1)$. Therefore, in further analysis only 84 patients were taken into consideration. No acute stent thrombosis was observed.

Clinical follow-up data were available in all patients at 12, 24 and 36 months (Table 4). At 3 years (median: 35 months, interquartile range [IQR] 32-39 months) the MACE incidence was 19\% $(\mathrm{n}=16)$. There were 2 cardiac deaths (heart failure deterioration), 3 deaths caused by cancer (lung cancer -2 , pancreas cancer -1 ), 5 cases of MI (MI caused by lesions within deployed stents 2 cases and lesions in other vessels -3 cases) and 9 (10.7\%) TLR cases. Seven TLR cases were treated with PCI, and 2 patients were referred for CABG. There were no statistical differences between BiOSS LIM stents, sirolimus-eluting stents, everolimus-eluting metallic stents and Absorb BVS stents in terms of MACE or TLR rates (Table 5).

\section{Logistic regression analysis}

Table 6 and Table 7 presents logistic regression analyses for MACE and TLR, respectively. In multivariate analysis regarding MACE rate NSTE-ACS and STEMI were associated with worse clinical outcome. And in the case of TLR rate in regression analysis, NSTE-ACS, STEMI and SB stenting were associated with worse clinical outcome, but proximal optimization technique (POT) was associated with better clinical outcome.

\section{Discussion}

The main findings of this paper are: 1 ) distal LM stenosis was mainly treated with 1 stent (provisional T-stenting [PTS]), 2) 3-year MACE and TLR rates were $19 \%$ and $10.7 \%$, respectively, 3 ) the clinical outcomes between dedicated bifurcation stents BiOSS and rDES were similar, 4) optimization techniques, especially POT, improved clinical outcomes.

The continuous advancement of angioplasty procedures broadens the range of lesions, which could be safely treated with PCI. Bifurcation stenosis in distal LM stem is one of such cases and its rate is systematically increasing in the population of patients subjected to PCI [12]. This study showed a high rate of device success $(100 \%)$ with favorable acute and long-term clinical results expressed by MACE rate at 12 as well as 36 months, $9.5 \%$ and $19 \%$, respectively. It is worth mentioning that in the original paper by Serruys et al. [13], 12 -month cumulative rate of major adverse cardiac or cerebrovascular events in a population of patients with low SYNTAX score (0-22) was $14.7 \%$ and with intermediate SYNTAX score (23-32) $-16.7 \%$. Also, the present results are in agreement with recently published 3-year results of the EXCEL trial, in which MACE and TLR rates were $18.2 \%$ and $9.5 \%$, respectively [2]. Moreover, the present study population was severely diseased, with a rate of diabetes (36.7\%), prior MI $(66.7 \%)$ and prior PCI $(60 \%)$ higher than in other studies assessing bifurcation treatment, respectively, $11-25.7 \%, 19.5-46 \%$ and $11.3-37.1 \%$ [13-18].

European Bifurcation Club recommends provisional SB stenting as standard strategy for treatment of coronary bifurcation. Although there are lesions for which PTS is not an optimal approach, the need for an alternative strategy is relatively rare in most lesions. Similar results were obtained in the presented registry, most bifurcations (83.3\%) were treated with PTS strategy and of importance is that $51.1 \%$ of cases were true bifurcations. As it was proved earlier PTS strategy ensures the best angiographic and clinical outcomes in a majority of studies [14]. Moreover, Kim et al. [7] as well as 
Table 5. Three-year clinical results — subgroup analysis.

\begin{tabular}{lccccc}
\hline Parameter & \multicolumn{4}{c}{ Three-year follow-up } \\
\cline { 2 - 6 } & $\begin{array}{c}\text { Whole } \\
(\mathbf{n}=84)\end{array}$ & $\begin{array}{c}\text { BiOSS LIM } \\
(\mathbf{n}=32)\end{array}$ & $\begin{array}{c}\text { SES } \\
(\mathbf{n}=26)\end{array}$ & $\begin{array}{c}\text { EES } \\
(\mathbf{n}=17)\end{array}$ & $\begin{array}{c}\text { BVS } \\
(\mathbf{n}=9)\end{array}$ \\
\hline MACE & $16(19.0 \%)$ & $6(18.8 \%)$ & $6(23.1 \%)$ & $3(17.6 \%)$ & $1(11.1 \%)$ \\
All-cause death & $5(5.9 \%)$ & $1(3.1 \%)$ & $3(11.5 \%)$ & $0(0 \%)$ & $1(11.1 \%)$ \\
Cardiac death & $2(2.4 \%)$ & $1(3.1 \%)$ & $0(0 \%)$ & $1(5.9 \%)$ & $0(0 \%)$ \\
Myocardial infarction & $5(5.9 \%)$ & $1(3.1 \%)$ & $2(7.7 \%)$ & $1(5.9 \%)$ & $1(11.1 \%)$ \\
Target lesion revascularization & $9(10.7 \%)$ & $4(12.5 \%)$ & $4(15.4 \%)$ & $1(5.9 \%)$ & $0(0 \%)$ \\
\hline
\end{tabular}

BVS - bioresorbable vascular scaffold; EES - metallic everolimus-eluting stent; MACE - major adverse cardiovascular events; SES — metallic sirolimus eluting stent

Table 6. Logistic regression for major adverse cardiovascular events at 3-year follow-up.

\begin{tabular}{|c|c|c|c|c|}
\hline \multirow[t]{2}{*}{ Variate } & \multicolumn{2}{|c|}{ Univariate analysis } & \multicolumn{2}{|c|}{ Multivariate analysis } \\
\hline & OR (95\% CI) & $\mathbf{P}$ & OR (95\% Cl) & $\mathbf{P}$ \\
\hline BiOSS vs. DES & $0.958(0.721-1.355)$ & 0.634 & & \\
\hline Sex: female vs. male & $0.821(0.490-1.331)$ & 0.542 & & \\
\hline Age [increase per 1 year] & $1.213(0.693-1.459)$ & 0.365 & & \\
\hline NSTE-ACS & $1.770(1.390-2.879)$ & 0.005 & $1.922(1.441-4.210)$ & 0.038 \\
\hline STEMI & $2.365(1.772-4.222)$ & 0.003 & $3.021(2.321-6.409)$ & 0.001 \\
\hline Diabetes mellitus & $1.851(1.281-2.169)$ & 0.028 & & \\
\hline Prior MI & $1.543(0.780-2.004)$ & 0.652 & & \\
\hline Prior $\mathrm{PCl}$ & $1.329(0.602-1.841)$ & 0.411 & & \\
\hline Coronary artery bypass graft & $1.201(0.883-2.261)$ & 0.653 & & \\
\hline Chronic kindey disease & $1.781(0.833-3.099)$ & 0.201 & & \\
\hline True bifurcation & $1.899(1.004-2.102)$ & 0.044 & & \\
\hline Side branch stenting & $1.260(0.778-1.901)$ & 0.247 & & \\
\hline Fnal kissing balloon & $0.722(0.567-1.114)$ & 0.061 & & \\
\hline Proximal optimization technique & $0.882(0.491-0.997)$ & 0.042 & & \\
\hline
\end{tabular}

$\mathrm{Cl}$ - confidence interval; DES - drug eluting stent; $\mathrm{MI}$ - myocardial infarction; NSTE-ACS - non-ST-elevation acute coronary syndrome; STEMI - ST-elevation myocardial infarction; OR — odds ratio; $\mathrm{PCl}$ - percutaneous coronary intervention

Table 7. Logistic regression for target lesion revascularization at 3-year follow-up.

\begin{tabular}{|c|c|c|c|c|}
\hline \multirow[t]{2}{*}{ Variate } & \multicolumn{2}{|c|}{ Univariate analysis } & \multicolumn{2}{|c|}{ Multivariate analysis } \\
\hline & OR (95\% Cl) & $\mathbf{P}$ & OR (95\% Cl) & $\mathbf{P}$ \\
\hline BiOSS vs. DES & $0.923(0.701-1.295)$ & 0.441 & & \\
\hline Sex: female vs. male & $0.781(0.540-1.119)$ & 0.622 & & \\
\hline Age [increase per 1 year] & $1.331(0.713-1.521)$ & 0.431 & & \\
\hline NSTE-ACS & $1.550(1.430-2.121)$ & 0.034 & $2.211(1.642-5.110)$ & 0.008 \\
\hline STEMI & $2.198(1.473-3.761)$ & 0.015 & $2.771(1.325-7.209)$ & 0.001 \\
\hline Diabetes mellitus & $1.651(1.191-2.009)$ & 0.018 & & \\
\hline Prior MI & $1.553(0.612-1.834)$ & 0.772 & & \\
\hline Prior $\mathrm{PCl}$ & $1.511(0.709-1.927)$ & 0.616 & & \\
\hline Coronary artery bypass graft & $1.321(0.893-2.012)$ & 0.499 & & \\
\hline Chronic kidney disease & $1.238(0.653-2.387)$ & 0.105 & & \\
\hline True bifurcation & $1.669(1.214-2.342)$ & 0.034 & & \\
\hline Side branch stenting & $1.345(1.009-1.699)$ & 0.047 & $1.141(1.002-1.881)$ & 0.042 \\
\hline Final kissing balloon & $0.632(0.437-0.991)$ & 0.041 & & \\
\hline Proximal optimization technique & $0.512(0.322-0.799)$ & 0.012 & $0.311(0.211-0.644)$ & 0.002 \\
\hline
\end{tabular}

$\mathrm{Cl}$ - confidence interval; DES — drug eluting stent; MI — myocardial infarction; NSTE-ACS — non-ST-elevation acute coronary syndrome; STEMI - ST-elevation myocardial infarction; OR — odds ratio; $\mathrm{PCl}$ — percutaneous coronary intervention 
others showed that one-stent technique is better than 2-stent technique [15].

There was a relatively low rate of stent implantation in SB (16.7\% of cases). This value is lower than in other studies, where the value ranges between $30 \%$ and $50 \%$ [16-18]. Only 15 cases required double stent technique, mainly performed with T-and-protrusion and culotte. Worth stressing is the fact that all culotte procedures were performed in distal LM with $2 \mathrm{BiOSS}^{\mathrm{LIM}}{ }^{\oplus}$ stents as described previously (Fig. 1) [19].

Predilatation of MV prior to stenting is the common approach, when routine SB dilation is unnecessary. Nevertheless, in the presence of severe SB ostial stenosis it should be considered. In the presented registry MV predilatations were performed in $76.7 \%$ cases and SB predilatations in $50 \%$. However, one has to keep in mind that the potential advantages of SB dilatation include increased ostial SB lumen, facilitated rewiring of the SB after stenting and avoidance of rewiring and post-dilatation of SB after implantation of MV stent [20].

Appropriate stent apposition in the proximal MV is achieved by POT, which is performed by dilating the proximal MV stent from the proximal stent edge to just proximal to the carina, using a short oversized balloon. POT facilitates SB access, reduces risk of accidental abluminal rewiring, lowers the risk of stent distortion by catheter collision, and enhances scaffolding at the SB ostium. Thus, POT should be considered a standard step in bifurcation treatment. Also final kissing balloon technique (FKB) optimizes the procedure [14]. Unfortunately, in the present paper rates of POT and FKB were relatively low, $56.7 \%$ and $43.3 \%$, respectively. This could be caused by the fact that only recently POT is strongly recommended by the European Bifurcation Club, and in cases of $\mathrm{FKB}$ - that only rarely 2 -stent technique was used where FKB is obligatory. Also, in $37.8 \%$ of cases dedicated bifurcation $\mathrm{BiOSS}^{\circledast}$ stents were implanted. The stepped design of the BiOSS $^{\circledR}$ stent delivery balloon theoretically was to ensure a FKB- and POT-like effect, thus allowing operators to frequently omit this part of the procedure. However, as was shown in POLBOS I trial not performing FKB and POT was associated with worse clinical outcomes and is a trend in larger late lumen loss, whereas in the NORDIC 3 study it was proved that FKB reduced angiographic side branch restenosis, especially in patients with true bifurcation lesions [21, 22]. These findings were confirmed in the MITO Registry [23]. Also, worth

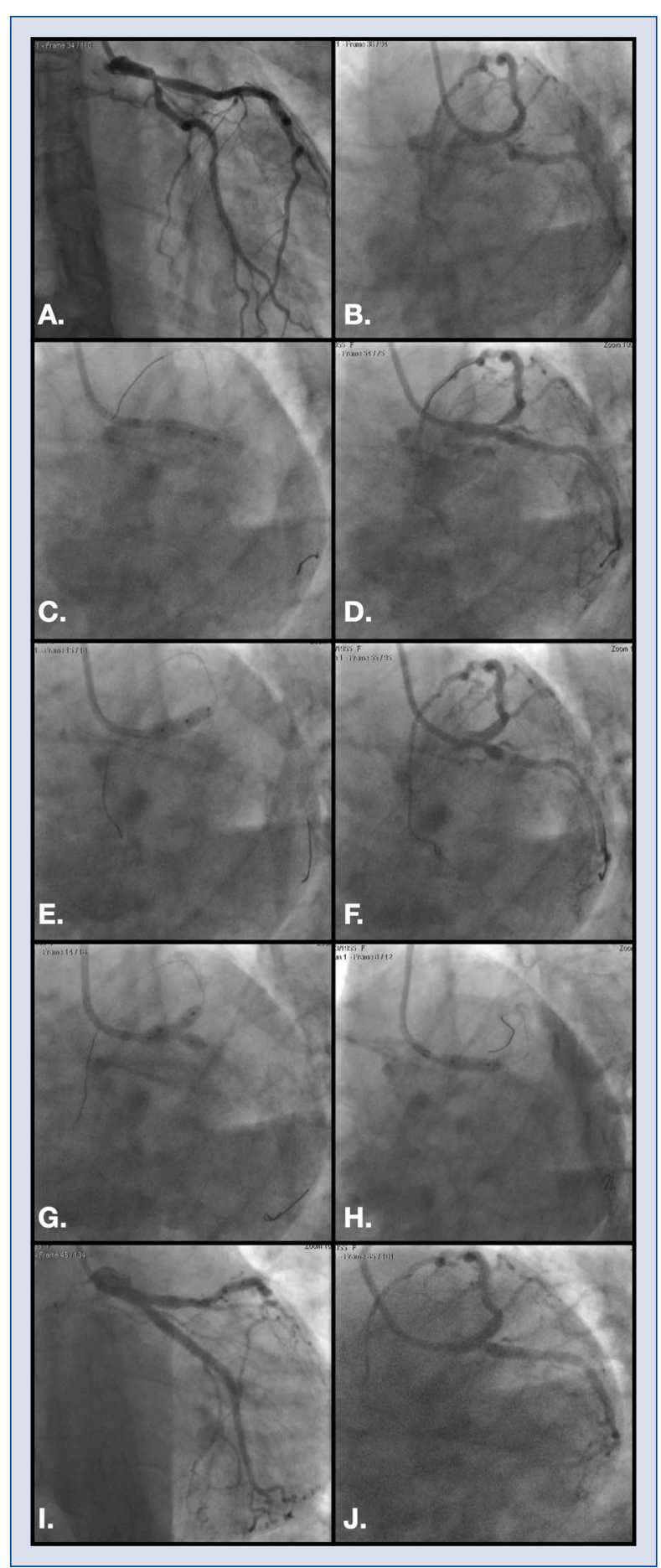

Figure 1. Two BiOSS stent implantation within distal left main; A, B. Initial views; C, D. First BiOSS LIM implantation in left main-left circumflex artery (LM-LCX); E, F. Second BiOSS LIM implantation in the left main-left ascending dimension artery (LM-LAD); G. Final kissing balloon; H. Proximal optimization technique; I, J. Final views.

stressing is the fact that the negative impact of true bifurcation and positive impact of $\mathrm{FKB}$ on MACE 
and TLR rates were also confirmed in our logistic regression analysis.

Although the procedure was performed on LM stenosis, most cases were performed via the radial access $(93.3 \%)$ and $6 \mathrm{~F}$ when guiding catheter was used (93.3\%). This approach was associated with less risk of complications, such as severe bleeding or the need for blood transfusion.

Also, in $10 \%$ of cases where BVS were used, all cases were uneventful. The use of bioresorbable stents might present potential advantages compared with metallic DES for bifurcation treatment. Some limitations of currently available BVS, such as strut thickness and limited expansion capacity as well as the reports of increased late thrombosis influence the adoption of BVS as a standard strategy $[24,25]$. Nevertheless, in the literature Absorb BVS was successfully deployed in the distal LM [26-28]. This registry has several limitations that should be acknowledged. First of all, the sample size was relatively small and heterogenous, additionally no sample size calculation was performed. Other limitations of this study are its non-randomized manner and all known drawbacks of retrospective studies. Moreover, intravascular ultrasound imaging was used only in $27.8 \%$ of cases $(n=25)$, and mainly manual pullback was performed.

\section{Conclusions}

Percutaneous distal LM stenosis treatment is a safe and effective procedure, and PTS is the preferred technique. Both rDES as well as dedicated bifurcation stents BiOSS LIM ${ }^{\circledast}$ enabled a simple and fast bifurcation treatment option with a single stent and with comparable MACE and TLR rates.

\section{Conflict of interest: None declared}

\section{References}

1. Windecker S, Kolh P, Alfonso F, et al. 2014 ESC/EACTS Guidelines on myocardial revascularization: The Task Force on Myocardial Revascularization of the European Society of Cardiology (ESC) and the European Association for Cardio-Thoracic Surgery (EACTS)Developed with the special contribution of the European Association of Percutaneous Cardiovascular Interventions (EAPCI). Eur Heart J. 2014; 35(37): 2541-2619, doi: 10.1093/ eurhearti/ehu278, indexed in Pubmed: 25173339.

2. Stone G, Sabik J, Serruys P, et al. Everolimus-eluting stents or bypass surgery for left main coronary artery disease. N Engl J Med. 2016; 375(23): 2223-2235, doi: 10.1056/nejmoa1610227.

3. Capodanno D, Stone GW, Morice MC, et al. Percutaneous coronary intervention versus coronary artery bypass graft surgery in left main coronary artery disease: a meta-analysis of rand- omized clinical data. J Am Coll Cardiol. 2011; 58(14): 1426-1432, doi: 10.1016/j.jacc.2011.07.005, indexed in Pubmed: 21939824.

4. Ferrante G, Presbitero P, Valgimigli M, et al. Percutaneous coronary intervention versus bypass surgery for left main coronary artery disease: a meta-analysis of randomised trials. EuroIntervention. 2011; 7(6): 738-746, 731, indexed in Pubmed: 21947626.

5. Qi X, Xu M, Yang H, et al. Comparing mortality and myocardial infarction between coronary artery bypass grafting and drugeluting stenting in patients with diabetes mellitus and multivessel coronary artery disease: a meta-analysis. Arch Med Sci. 2014; 10(3): 411-418, doi: 10.5114/aoms.2014.43734, indexed in Pubmed: 25097568.

6. Sadowski M, Gutkowski W, Raczyński G, et al. Acute myocardial infarction due to left main coronary artery disease in men and women: does ST-segment elevation matter? Arch Med Sci. 2015; 11(6): 1197-1204, doi: 10.5114/aoms.2015.56345, indexed in Pubmed: 26788080.

7. Kim WJ, Kim YH, Park DW, et al. Comparison of single- versus two-stent techniques in treatment of unprotected left main coronary bifurcation disease. Catheter Cardiovasc Interv. 2011; 77(6): 775-782, doi: 10.1002/ccd.22915, indexed in Pubmed: 21520380.

8. Ferenc M, Ayoub M, Büttner HJ, et al. Long-term outcomes of routine versus provisional T-stenting for de novo coronary bifurcation lesions: five-year results of the Bifurcations Bad Krozingen I study. EuroIntervention. 2015; 11(8): 856-859, doi: 10.4244/EIJV11I8A175, indexed in Pubmed: 26696453.

9. Medina A, Lezo JS, Pan M. A New Classification of Coronary Bifurcation Lesions. Revista Española de Cardiología (English Edition). 2006; 59(2): 183, doi: 10.1016/s1885-5857(06)60130-8.

10. Thygesen K, Alpert JS, Jaffe AS, et al. Third universal definition of myocardial infarction. Circulation. 2012; 126(16): 2020-2035, doi: 10.1161/cir.0b013e31826e1058.

11. Bil J, Gil RJ, Vassilev D, et al. Dedicated bifurcation paclitaxeleluting stent BiOSS Expert ${ }^{\circledR}$ in the treatment of distal left main stem stenosis. J Interv Cardiol. 2014; 27(3): 242-251, doi: 10.1111/joic.12119, indexed in Pubmed: 24708143.

12. Costa RA, Costa MA, Moussa ID. Bifurcation lesion morphology and intravascular ultrasound assessment. Int J Cardiovasc Imaging. 2011; 27(2): 189-196, doi: 10.1007/s10554-011-9846-x, indexed in Pubmed: 21409536.

13. Serruys PW, Morice MC, Kappetein AP, et al. SYNTAX Investigators. Percutaneous coronary intervention versus coronaryartery bypass grafting for severe coronary artery disease. $\mathrm{N}$ Engl J Med. 2009; 360(10): 961-972, doi: 10.1056/NEJMoa0804626, indexed in Pubmed: 19228612.

14. Lassen JF, Holm NR, Banning A, et al. Percutaneous coronary intervention for coronary bifurcation disease: 11th consensus document from the European Bifurcation Club. EuroIntervention. 2016; 12(1): 38-46, doi: 10.4244/EIJV12I1A7, indexed in Pubmed: 27173860.

15. Chen SL, Zhang Y, Xu Bo, et al. Five-year clinical follow-up of unprotected left main bifurcation lesion stenting: one-stent versus two-stent techniques versus double-kissing crush technique. EuroIntervention. 2012; 8(7): 803-814, doi: 10.4244/EIJV8I7A123, indexed in Pubmed: 23171801.

16. Costa RA, Abizaid A, Abizaid AS, et al. Procedural and early clinical outcomes of patients with de novo coronary bifurcation lesions treated with the novel Nile PAX dedicated bifurcation polymer-free paclitaxel coated stents: results from the prospective, multicentre, non-randomised BIPAX clinical trial. EuroIntervention. 2012; 7(11): 1301-1309, doi: 10.4244/EIJV7I11A205, indexed in Pubmed: 22433193. 
17. Magro M, Girasis C, Bartorelli AL, et al. Acute procedural and six-month clinical outcome in patients treated with a dedicated bifurcation stent for left main stem disease: the TRYTON LM multicentre registry. EuroIntervention. 2013; 8(11): 1259-1269, doi: DOI: 10.4244/EIJV8I11A194, indexed in Pubmed: 23538155.

18. Ormiston JA, Lefèvre T, Grube E, et al. First human use of the TAXUS Petal paclitaxel-eluting bifurcation stent. EuroIntervention. 2010; 6(1): 46-53, doi: 10.4244/, indexed in Pubmed: 20542797.

19. Vassilev D, Mateev H, Alexandrov A, et al. Double bifurcation optimization stent system technique for left main stenosis. J Interv Cardiol. 2014; 27(6): 570-573, doi: 10.1111/joic.12155, indexed in Pubmed: 25224296.

20. Pan M, Medina A, Romero M, et al. Assessment of side branch predilation before a provisional T-stent strategy for bifurcation lesions. A randomized trial. Am Heart J. 2014; 168(3): 374-380, doi: 10.1016/j.ahj.2014.05.014, indexed in Pubmed: 25173550.

21. Niemelä M, Kervinen K, Erglis A, et al. Randomized comparison of final kissing balloon dilatation versus no final kissing balloon dilatation in patients with coronary bifurcation lesions treated with main vessel stenting: the Nordic-Baltic Bifurcation Study III. Circulation. 2011; 123(1): 79-86, doi: 10.1161/CIRCULATIONAHA.110.966879, indexed in Pubmed: 21173348.

22. Gil RJ, Bil J, Džavík V, et al. Regular drug-eluting stent vs dedicated coronary bifurcation BiOSS expert stent: Multicenter open-label randomized controlled POLBOS I trial. Can J Cardiol. 2015; 31(5): 671-678, doi: 10.1016/j.cjca.2014.12.024, indexed in Pubmed: 25828372.
23. Takagi K, Ielasi A, Basavarajaiah S, et al. The impact of main branch restenosis on long term mortality following drug-eluting stent implantation in patients with de novo unprotected distal left main bifurcation coronary lesions: the Milan and New-Tokyo (MITO) Registry. Catheter Cardiovasc Interv. 2014; 84(3): 341348, doi: 10.1002/ccd.25178, indexed in Pubmed: 24038911.

24. Dudek D, Rzeszutko $€$, Zasada W, et al. Bioresorbable vascular scaffolds in patients with acute coronary syndromes: the POLAR ACS study. Pol Arch Med Wewn. 2014; 124(12): 669-677, indexed in Pubmed: 25563622.

25. Bil J, Gil RJ. Bioresorbable vascular scaffolds-what does the future bring? J Thorac Dis. 2016; 8(8): E741-E745, doi: 10.21037/ jtd.2016.05.80, indexed in Pubmed: 27619478.

26. Grundeken MJ, Kraak RP, de Bruin DM, et al. Three-dimensional optical coherence tomography evaluation of a left main bifurcation lesion treated with ABSORB ${ }^{\circledR}$ bioresorbable vascular scaffold including fenestration and dilatation of the side branch. Int J Cardiol. 2013; 168(3): e107-e108, doi: 10.1016/j. ijcard.2013.07.255, indexed in Pubmed: 23972365.

27. Cortese B, Orrego PS, Sebik R, et al. Biovascular scaffolding of distal left main trunk: experience and follow up from the multicenter prospective RAI registry (Registro Italiano Absorb). Int J Cardiol. 2014; 177(2): 497-499, doi: 10.1016/j.ijcard.2014.08.081, indexed in Pubmed: 25205485.

28. Tanaka A, Latib A, Kawamoto H, et al. Clinical outcomes following bifurcation double-stenting with bioresorbable scaffolds. Catheter Cardiovasc Interv. 2016; 88(6): 854-862, doi: 10.1002/ /ccd.26579, indexed in Pubmed: 27184769. 